\title{
DIFFERING CALCIUM REQUIREMENTS FOR REGULATORY EFFECTS OF ATP, ATPYS AND ADENOSINE ON $0 \div$ RESPONSES OF HUMAN NEUTROPHILS
}

Peter A. Ward*, Thomas W. Cunningham, Blair A. M. Walker, and Kent J. Johnson

\author{
The University of Michigan Medical School \\ Department of Pathology \\ 1301 Catherine St. \\ Ann Arbor, MI 48109
}

Received June 10, 1988

In formyl peptide stimulated human neutrophils the enhancement of $0 \frac{\overline{2}}{2}$ responses by ATP and ATPYS requires extracellular calcium. In contrast, the inhibitory effects of adenosine are independent of a calcium requirement. Rates of $0 \div$ generation are not affected by these adenine compounds. Rather, ATP and ATPyS cause a sustained period of generation whereas adenosine causes an abrupt early termination of the $0 \div$ response. The differing calcium requirements for regulatory effects of adenine compounds on $0 \frac{1}{2}$ responses of stimulated neutrophils suggests that ATP (or ATPyS) and adenosine may exert their effects at different points in the pathway of signal transduction events. 1988 academic Press, Inc.

Superoxide anion $(0 \div)$ responses of human neutrophils stimulated by the chemotactic peptide, $\mathrm{N}$-formyl-Met-Leu-Phe (FMLP) are enhanced by the presence of ATP or its analogues such as ATPYS $(1,2)$ and inhibited by the presence of adenosine $(3,4)$. The current studies were designed to assess if extracellular calcium is required for the regulatory effects of ATP, ATPYS and adenosine on $0 \div \frac{1}{2}$ responses of fMLP stimulated human neutrophils.

\section{MATERIALS AND METHODS}

Reagents. Unless otherwise indicated, all chemicals were purchased from Sigma Chemical Co. (St. Louis, MO).

Preparation of Neutrophils. Venous blood was obtained from healthy adult humans, using a 1:6 ratio of acid-citrate dextrose and blood, yielding a

* To whom correspondence should be addressed.

Abbreviations used are: HBSS, Hanks balanced salt solution; fMLP, N-formylMet-Leu-Phe; ATPyS, adenosine 5',-0-(3-thiotriphosphate). 
final citrate concentration of $2.5 \mathrm{mM}$. Neutrophils were fractionated by Ficoll-Hypaque techniques as described in detail elsewhere (1). Generation of $0 \div$ was determined by superoxide dismutase inhibitable reduction of ferricytochrome c (1).

Reactions Conditions. As indicated, neutrophils $\left(5 \times 10^{6} / \mathrm{m} 1\right)$ were incubatẹd

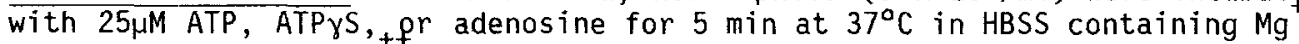
and, as indicated, $\mathrm{Ca}$. Control groups were similarily treated but in the absence of adenine compound. The cells were then washed once, resuspended in HBSS lacking calcium, and then placed into the reaction mixtures, to which $1.8 \mathrm{mM}$ calcium was added where indicated. The mixtures were warmed for $5 \mathrm{~min}$ at $37^{\circ} \mathrm{C}$ and then stimulated with fMLP and the $0 \div$ responses measured. MgSO $(0.4 \mathrm{mM})$ was constantly present in all salt solutions, unless otherwise indicated.

Statistical Analysis. Data were expressed as $\bar{x} \pm$ standard error of the mean (S.E.M.). A paired t-test was used to compare the response between two treatments. Statistical significance was defined as $p<0.05$. Specifics regarding the number of experiments, etc., are contained in the text or within each Table.

\section{RESULTS}

Contrasting Requirements of Calcium for Regulatory Effects of ATP, ATPYS and Adenosine on $0 \dot{z}$ Responses of Stimulated Neutrophils.

In order to determine if calcium is required for the enhancing effects of ATP and ATPYS on $0 \dot{2}$ generation in fMLP stimulated neutrophils, experiments

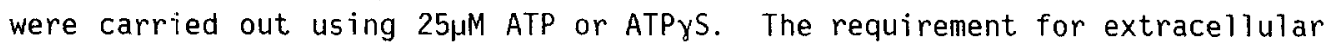
calcium was assessed employing Hanks buffered salt solution (containing $0.4 \mathrm{mM}$ $\mathrm{Mg}^{++}$) in the presence or absence of $1.8 \mathrm{mM}$ calcium. When calcium was present both during exposure of neutrophils to ATP or ATPyS ("prewash" phase) as well as during exposure to FMLP ("postwash" phase), there was a statistically significant rise $\left(25.8 \%\right.$ and $38.1 \%$ ) in the $0 \frac{\dot{2}}{2}$ response (Table I).

If calcium was omitted during "prewash" cell exposure to ATP or ATPyS but added in the subsequent "postwash" exposure of neutrophils to fMLP, there was no increase in the $0 \frac{\overline{2}}{2}$ response. In contrast, if calcium was present when cells were exposed to ATP or ATPyS but absent in the cell suspension when fMLP was added, there was a statistically significant enhancement $(40.3 \%$ and $42.5 \%$ ) of the $0 \overline{2}$ response. Not surprisingly, in the continuous absence of calcium, not only was the $0 \frac{\overline{2}}{2}$ response to fMLP blunted, no increment occurred in cells that had also been exposed to ATP or ATPYS. These data indicate that the ability of ATP and ATPyS to bring about enhanced $0 \div$ responses in fMLP stimulated neutrophils requires the presence of extracellular calcium at the time of neutrophil contact with nucleotide.

Using a similar protocol, a companion series of studies was carried out to determine if the inhibitory effects of adenosine on $0 \dot{2}$ responses in FMLP stimulated neutrophils require the presence of extracellular calcium. As shown in Table II, it is evident that the inhibitory effects of adenosine were independent of a requirement for extracellular calcium. In the con- 
Table I

Requirement of Calcium for Enhancing Effects of ATP and ATP on Superoxide Responses:

\begin{tabular}{|c|c|c|c|c|}
\hline $\begin{array}{c}\text { material } \\
\text { added during } \\
\text { prewash }\end{array}$ & $\frac{\text { presence of }}{\text { prewash }}$ & $\frac{\text { calcium }}{\text { postwash }}$ & $\begin{array}{l}0 \dot{2} \text { production } \\
(\text { nmol/30 min) }\end{array}$ & $\begin{array}{c}\text { change } \\
\text { (percent) }\end{array}$ \\
\hline \multicolumn{5}{|l|}{ Exp. I } \\
\hline HBSS & + & + & $21.3 \pm 4.7$ & \\
\hline ATP & + & + & $26.8 \pm 4.3$ & $+25.8(p<.004)$ \\
\hline HBSS & - & + & $21.1 \pm 4.1$ & \\
\hline ATP & - & + & $20.8 \pm 4.4$ & -1.4 (p, N.S. ) \\
\hline HBSS & + & - & $16.6 \pm 3.4$ & \\
\hline ATP & + & - & $22.3 \pm 4.1$ & $+40.3(\mathrm{p}<.03)$ \\
\hline HBSS & - & - & $15.5 \pm 3.0$ & \\
\hline ATP & - & - & $15.2 \pm 2.6$ & -1.9 (p,N.S. ) \\
\hline \multicolumn{5}{|l|}{ Exp. II } \\
\hline HBSS & + & + & $14.7 \pm 1.70$ & \\
\hline ATP $\gamma \mathrm{S}$ & + & + & $20.3 \pm 2.62$ & $+38.1 \quad(p<.008)$ \\
\hline HBSS & - & + & $15.9+1.70$ & \\
\hline ATPYS & - & + & $15.6 \pm 1.53$ & -1.8 (p,N.S.) \\
\hline HBSS & + & - & $12.0 \pm 1.49$ & \\
\hline ATPYS & + & - & $17.1 \pm 210$ & $+42.5 \quad(\mathrm{p}<.003)$ \\
\hline HBSS & - & - & $12.3 \pm 1.70$ & \\
\hline ATPyS & - & - & $12.1 \pm 1.63$ & $-1.6(\mathrm{p}, \mathrm{N} . \mathrm{S})$. \\
\hline
\end{tabular}

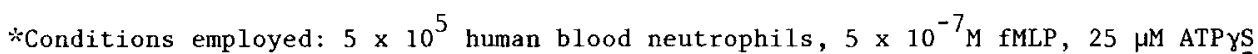
or ATP. In Experiment $I, n=4$; in Experiment II, $n=8.0 \frac{-}{2}$ data are expressed as $x$ \pm S.E.M.

*HHSS, Hanks balanced salt solution, Tris buffered, pH 7.4.

*w*When present, the concentration of calcium was $1.8 \mathrm{mM}$. "Prewash" refers to the first treatment of neutrophils (presence or absence of ATP or ATPyS) while "postwash" refers to time of addition of fMLP (in the absence of ATP or ATPyS). itikfor statistical comparisons, $0 \dot{j}$ values obtained by cell exposure to ATP or ATPyS were compared to the HBSS values in each of the pairs within the experimental groupings. N.S., not significant.

tinuing presence of calcium, adenosine caused a $33 \%$ inhibition in the $0 \frac{1}{2}$ responses. Omission of calcium in the salt solution when cells were exposed to adenosine ("prewash" phase) followed by addition of calcium when fMLP was

Table II

Lack of Requirement of Calcium for Inhibitory Effects of Adenosine on Superoxide Responses*

\begin{tabular}{|c|c|c|c|c|}
\hline $\begin{array}{c}\text { material } \\
\text { added during } \\
\text { prewash }\end{array}$ & $\frac{\text { presence }}{\text { prewash }}$ & $\frac{\text { of calcium }}{\text { postwash }}$ & $\begin{array}{l}0 \div \text { production } \\
(\text { iाmul/30 min) }\end{array}$ & $\begin{array}{c}\text { change } \\
\text { (percent) }\end{array}$ \\
\hline HBSS & + & + & $10.0 \pm 1.56$ & \\
\hline adenosine & + & + & $6.67 \pm 1.34$ & $-33.3(\mathrm{p}<.025)^{\star *}$ \\
\hline HBSS & - & + & $8.80 \pm 1.84$ & \\
\hline adenosine & - & + & $5.14 \pm 1.77$ & $-41.5(p<.05)$ \\
\hline HBSS & + & - & $7.23 \pm 1.46$ & \\
\hline adenosine & + & - & $5.09 \pm 1.39$ & $-29.5(p<.035)$ \\
\hline HBSS & - & - & $7.61 \pm 1.13$ & \\
\hline adenosine & - & - & $4.18 \pm 0.68$ & $-45.0 \quad(p<.02)$ \\
\hline
\end{tabular}

*Conditions employed: $5 \times 10^{5}$ human blood neutrophils, $5 \times 10^{-7} \mathrm{M}$ fMLP, $25 \mu \mathrm{M}$ adenosine. The number of experiments was 6 . 0ther experimental details are as described in Table 1 .

**Paired t-test, comparing $0 \div$ values of cells subjected to the presence or absence of adenosine in each of the four pairs of data. 


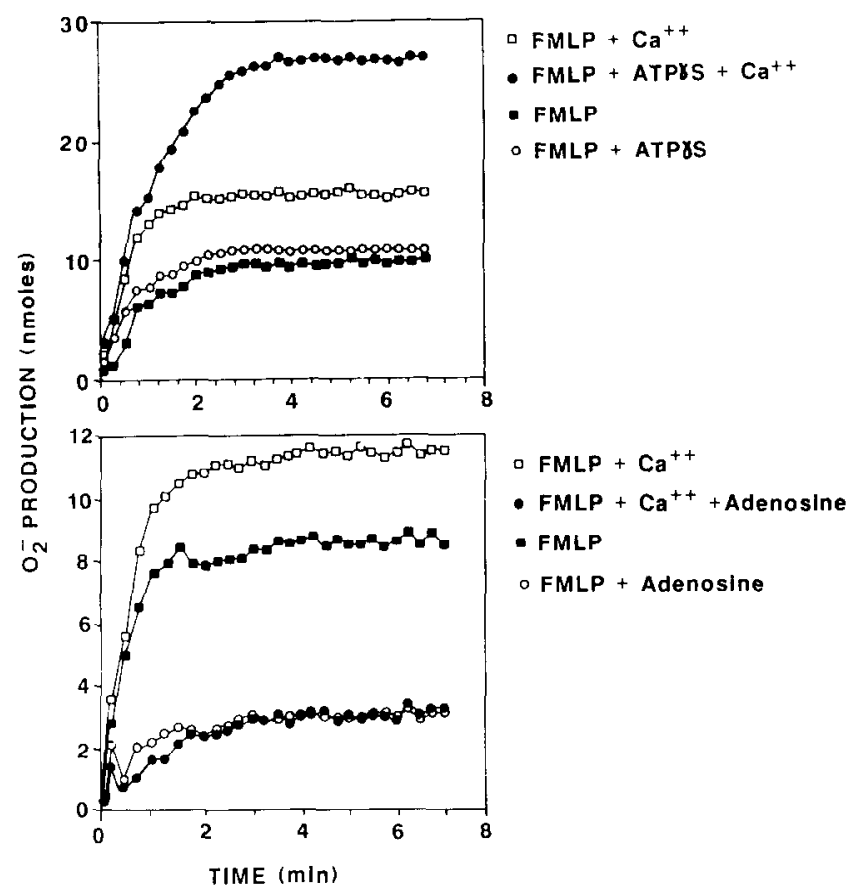

Figure 1: Upper frame, generation of $0 \div$ by $10^{6}$ human neutrophils stimulated at time 0 with $5 \times 10^{-7} \mathrm{M}$ fMLP in the presence or absence of $10 \mu \mathrm{M} \mathrm{ATP \gamma S}$, as a function of the presence or absence of $1.8 \mathrm{mM}$ extracellular calcium. Lower frame, similar studies employing $10 \mu \mathrm{M}$ adenosine in the presence or absence of calcium.

subsequently added ("postwash" phase) resulted in a $41.5 \%$ reduction of the $0 \frac{1}{2}$ response. The presence of calcium during cell exposure to adenosine but omission of calcium when fMLP was added to the cells resulted in a $29.5 \%$ reduction in the $0 \dot{2}$ response. Finally, even in the continuing absence of calcium, adenosine was able to inhibit (by $45.0 \%$ ) the $0 \frac{1}{2}$ response. Thus, the inhibitory effects of adenosine on $0 \dot{2}$ responses of fMLP stimulated human neutrophils are independent of a requirement for extracellular calcium, in striking contrast to the calcium requirement for the enhancing effects of ATP and ATPYS.

Changes in Rates of $0 ;$ Generation. Experiments were carried out to determine if ATP, ATPYS and adenosine affect the rates of $0 \overline{2}$ generation in the presence and absence of calcium. Representative data from four separate experiments are shown in Figure 1 . In fMLP stimulated neutrophils, there was a prompt $0 \dot{2}$ response which reached a plateau within $1.5 \mathrm{~min}$. (Figure 1 , upper frame). Using similar conditions in the presence of $10 \mu \mathrm{M}$ ATPYS, the initial rates of $0 \div$ production were unaffected as defined by statistical analysis (data not shown), but the presence of ATPyS caused a sustained production of $0 \dot{2}$, the plateau not being reached until approximately 3 min. When calcium was omitted from the salt solution, the total $0 \frac{\dot{2}}{2}$ response in fMLP stimulated 
cells was, as expected, greatly reduced, the plateau occurred earlier, and the presence of ATPYS was virtually without effect. Thus, the ability of ATPYS to enhance $0 \div 2$ responses of FMLP stimulated neutrophils requires extracellular calcium and is related to sustained periods of production of $0 \frac{1}{2}$ A similar pattern was found with ATP (data not shown).

Companion experiments were carried out with $10 \mu \mathrm{M}$ adenosine, the results of which are shown in Figure 1, lower frame. As expected, calcium was required for the maintenance of the $0 \div \frac{1}{2}$ response in FMLP stimulated neutrophils. The addition of adenosine, whether in the presence or absence of calcium, led to an abrupt cessation of the $0 \div \frac{1}{2}$ response. Although the initial rate of $0 \div$ production was similar to that found with stimulated cells in the absence of adenosine (data not shown), the most remarkable effect of adenosine was to cause very early termination (in <lmin) of the $0 \frac{1}{2}$ response, extracellular calcium not being necessary for this outcome.

\section{DISCUSSION}

ATP and ATPYS may "prime" neutrophils for enhanced superoxide responses to fMLP in a manner that is analogous to the effect of bacterial endotoxin (5) or very low leveis of either fMLP (6) or platelet activating factor (7). However, while ATP, per se, generates calcium transients $(1,8)$ other agents such as bacterial endotoxin and phorbol ester prime neutrophils but do not usually produce measurable calcium transients. In one sense, the ability of ATP or ATPYS to prime neutrophils for enhanced $0 \dot{2}$ responses might be analogous to the ability of calcium ionophore A23187 to alter neutrophils for enhanced $0 \div$ responses when subsequently stimulated with phorbol ester (9). Nucleotides could alter fMLP receptors, the g-binding proteins, protein kinase $C$ or the process of its translocation, or they might conceivably directly affect NADPH oxidase once the neutrophil has been activated. Alternatively, ATP and ATPYS could cause fusion of secondary granules to the cell membrane, resulting in an increase in numbers of fMLP receptors on the cell membrane. Since this fusion process is known to require the presence of extracellular calcium (10), the possibility that fMLP receptor adduction to the cell membrane is the explanation for the observed effects of the ATP compounds seems possible and is a current topic of study.

\section{ACKNOWLEDGEMENT}

This work has been supported by N.I.H. grants HL-31963, GM-29507, HL34635.

\section{REFERENCES}

1. Ward, P.A., Cunningham, T.W., McCulloch, K.K., Phan, S.H., Powe11, J. and Johnson, K.J. (1988) Lab. Invest. 58,37-47

2. Ward, P.A., Cunningham, T.W., McCulloch, K.K. and Johnson, K.J. (1988) Lab. Invest., 58:438-448 
3. Cronstein, B.N., Kramer, S.B., Weissmann, G., and Hirschhorn, R. (1983) J. Exp. Med. $158,1160-1177$

4. Roberts, P.A., Newby, A.C., Hallett, M.B., and Campbe 11, A.K. (1985) Biochem. J. 227, 669-674

5. Guthrie, L.A., McPhail, L.C., Henson, P.M. and Johnston, R.B., Jr. (1984) J. Exp. Med. 160,1656-1671

6. Gallin, J.I. and Fletcher, M.P. (1980) J. Immunol. 124, 1585-1588.

7. Dewald, B. and Baggiolini, M. (1985) Biochem. Biophys. Res. Comm. 128, 297-304

8. Kuhns, D.B., Wright, D.B., Nath, J., Kaplan, S.S., and Basford, R.E. (1988) Lab. Invest. 58: 448-453

9. Robinson, J.M., Badwey, J.A., Karnovsky, M.L., Karnovsky, M.J. (1984) Biochem. Biophys. Res. Comm. 122,734-739

10. Fletcher, M.P., Seligmann, B.E., and Gallin, J.I. (1981) J. Immunol. $\underline{128}, 941-948$ 